\title{
Determining the appropriate setting of lead-acid battery plate coating with sulfuric acid via response surface methodology
}

\author{
Chansiri Singhtaun $^{\mathrm{a}^{*}}$, Nuttaporn Viteejongjaroen ${ }^{\mathrm{b}}$ \\ ${ }^{a}$ Department of Industrial Engineering, Kasetsart University, 50 Ngamwongwan Rd. Chatuchak \\ Bangkok, 10900, Thailand \\ ${ }^{b}$ Master of Engineering Program in Engineering Management, Kasetsart University, 50 Ngamwongwan Rd. Chatuchak \\ Bangkok, 10900, Thailand
}

\begin{abstract}
The purpose of this research is to determine the optimal setting for the sulfuric acid coating process in lead-acid battery production. The acid coating process is planned to be applied in the original pasting process of a case study factory in order to improve battery plate quality. To determine the optimal level of factors in the acid coating process, Response Surface Methodology (RSM) using Central Composite Design (CCD) with two replications was performed. The influence of acid roller pressure, acid flow rate and baking temperature were studied. The responses in this experiment were the percentage of dried plate moisture and the number of cracks on the plate surface. The analysis of variance for the designed experiment showed the significant influence of acid flow rate and curing temperature. According to the experiment results, the optimal setting of acid flow rate is at 7 liters/minute and the curing temperature is at $200^{\circ} \mathrm{C}$. The level of acid roller pressure is set at $0 \mathrm{MPa}$ to give the most benefit to the production condition. The experimental verification results showed that the average percentage of dried plate moisture increased by $4.74 \%$ and there were no cracks on the surface.
\end{abstract}

Keywords: Central composite design, lead-acid battery, response surface methodology, sulfuric acid

\section{Introduction}

Nowadays, the increasing concern about environmental problems turns global attention to renewable energy sources such as solar energy, wind power, hydropower etc. Renewable energy power systems incorporate a power generating component, an energy storage component, and the requisite control circuit [1]-[2]. The battery is a major energy back-up system that stores and supplies energy in a renewable energy power system. The lead-acid battery is a well-established battery system that holds a large share of the battery market especially in automotive, power back-up systems and stationary applications. The leadacid battery for automotive uses is studied in this paper. Two types of lead-acid battery are generally manufactured namely, wet-charged and dry charged batteries. The manufacturing process of both types of battery is similar, except for the charging step. They are made up of a positive electrode, a negative electrode and an electrolytic solution.

The manufacturing process of lead-acid batteries can be divided into ten stages. They are oxide milling, grid casting, the plate manufacturing process, battery assembly, formation, filling, the charge-discharge process, final assembly, inspection and dispatch [3]-[4]. The plate manufacturing process, which is a major stage, has been intensively researched to improve the quality of batteries for a long time. The process is that of applying a lead oxide paste on a lead alloy grid. There are five steps in the battery plate manufacturing process of the case study factory as follows.

\footnotetext{
* Manuscript received January 18, 2018; revised April 20, 2018.

Corresponding author. Tel.: +6-627-970-999; E-mail address: chansiri.s@ku.ac.th.

doi: $10.12720 /$ sgce.7.2.109-116
} 
1) Grid casting. Bars of lead alloy are melted in a 5-ton lead melting pot that is heated with a compressed natural gas heater at $110 \square{ }^{\circ} \mathrm{C}$ for 2 hours. The molten lead is then pumped into grid molds, which are then water cooled. After cooling, the mold is opened to discharge the grid.

2) Oxide milling. This process converts soft lead into lead oxide. Five tons of solid soft lead bars are melted. The molten lead is formed and cut into small cubes before being sent to the milling machine. In this machine, lead cubes collide and oxidize to form lead oxide. The separated lead oxide is then transferred into storage tanks called silos.

3) Paste mixing. Battery paste is made by mixing lead oxide with water, sulfuric acid and a range of additives in a fixed ratio. The temperature is controlled at not over $60^{\circ} \mathrm{C}$. The moisture of the paste after mixing is controlled in the range of $11 \%-13 \%$. This paste is then pasted onto the grids.

4) Pasting. During the pasting process, lead oxide paste is applied to the grid panels in a pasting machine to fill the spaces of the grid. The paste is pressed by pressure roller into the grid lattice.

5) Plate curing. Pasted plates are cured by storing them in ovens under carefully controlled conditions of temperature and humidity for 10 hours. Free lead in the paste converts to lead oxide. Finally, the plates are flash-dried in a high-temperature oven for 4 hours.

Plate quality improvement has been intensively studied by using several techniques such as alternative cell chemistries, the alternative cell design concept, improved materials, and physical modifications [5]. Improving materials by changing the alloy enhances paste adhesion and reduces corrosion. There are great efforts to make electrodes more efficient, to obtain better battery performance and also to improve the process of making these devices. For example, [6] studied the influence of five factors in the curing process on lead-acid performance. They are the proprieties of starting lead-oxide, the quantities of water and sulfuric acid added in the mixing stage, the paste mixing conditions (temperature, duration, and method), the curing conditions (temperature, humidity and duration of curing), and the stand time of the paste before pasting onto the grid. The results in [6] showed that the curing conditions are determinant for the modifications of the chemical and the phase composition of positive active mass, and for electrochemical performance. [7] placed importance on improving the pasting method by spraying acid on the pasted plate. The acid spray coated on the pasted plate reduced the number of cracks on the plate surface and enhanced curing because more moisture is maintained in the plate. The acid coating method has been introduced in the parent factory of the case study factory. Although it can improve plate quality, many disadvantages have been found. They are lead losses, waste extermination cost and working environmental problems [8]. In this research, acid coating is implemented in the pasting process with a different technique. The optimal setting of the process is set in order to improve two plate quality characteristics, which are plate moisture and the number of cracks on the plate surface.

To find the optimal setting of the new pasting condition, RSM is implemented. RSM is a collection of mathematical and statistical techniques that are useful for the modeling of an analysis of problems in which the response of interest is influenced by several variables and the objective is to optimize this response [9]. The relationship between response and the influencing factors is represented by the equation called the response surface equation. If the response is well modeled by a linear function of the independent variables, then the approximating function is the first-order model. If there is curvature in the system, then a polynomial of higher degree (the second-order model) must be used. CCD is the most popular class of experimental design used for fitting a second-order model because the model obtained from $\mathrm{CCD}$ is rotatable. With this property, this design provides equal precision of estimation in all directions. CCD is usually applied with $2^{\mathrm{k}}$ full factorial design ( $\mathrm{k}$ factors that are of interest and each has two levels). CCD comprises three components that are the $2^{\mathrm{k}}$ factorial points, the axial points that correspond to the selected Alpha value, and the center points. At the axial points, one variable is varied while the others are fixed at the center point. At the center points, all variables are set at the center point of its high and low level. The second-order model is optimized using the steepest ascent method.

\section{Methodology}

There are five steps in the research methodology as follows. 


\subsection{Problem definition and data collection}

There are two main quality problems found in the pasting process. The first defect is cracks observed as lines across the dried plate surface as shown in Fig 1 (a). A good condition plate should have no cracks as shown in Fig 1 (b). The crack makes a cleft between the paste and the spaces in the grid. The pastes finally slip off when moving to the next process. The other main defect is that the dried plates are too wet. The surface of the dried plates is soft. It is easily observed at the edge of plates as shown in Fig 2 (a). This defect causes the dried plates to stick to each other. Pastes slip off and holes remain on the plate after they are separated. A good condition plate has a smooth clean surface as shown in Fig 2 (b). These two defects are indicated by dried plate moisture, which is controlled at $9.5 \pm 1.0 \%$ or between $8.5 \%$ and $10.5 \%$.

The average moisture of 30 sampling dried plates is $9.09 \%$ and the standard deviation is $0.21 \%$. The natural limit lies between $9.09 \pm 3 \times 0.21$ or $8.37 \%$ to $9.63 \%$. The plate moisture is close to the lower specification limit that has a high chance to get cracks. According to the operator, too wet plates can be clearly observed by the operators when the plates come out from the flash oven while cracks are seen with a microscope at the end of plate manufacturing process. Therefore, the flash oven is adjusted to prevent the sticking plate problem. The case study factory needs to reduce the chance of producing cracked plates by increasing the plate moisture. Moreover, to increase quality, the case study factory has developed new technology for sulfuric acid coating. However, when this technology was used in the parent company, acid spray coating was performed. There are a lot of disadvantages of spray coating due to acid diffusion, such as worker acid exposure, acid losses, and thin coated film. Sulfuric acid cannot be reused because the particles will block up the nozzles. The overflow sulfuric acid needs special treatment and air treatment is required. Therefore, the parent company intends to set up the smear coating process using rollers in the case study factory. The acid rollers are installed after the pressure roller in the original pasting process as shown in Fig. 3. After the paste is pressed into the grid by pressure roller, the plates move between acid rollers. The pressure of the acid rollers can be adjusted. Above the top roller, sulfuric acid is poured through a pierced polyvinyl chloride (PVC) pipe. Sulfuric acid pumped from the storage tank flows from the top roller to the pressed plates and the bottom roller. The flow rate can be adjusted by valve and servo motor. The used sulfuric acid is reused after a sedimentation process. The specific gravity of sulfuric acid in the acid tank is measured by hydrometer and controlled in the range of $1.15 \pm 0.05$ at a temperature of $20^{\circ} \mathrm{C}$. The acid coated plate is then transported by conveyor to the flash oven. The conveyor speed and baking temperature can be adjusted. The objective of the experiment is to find the optimal settings for the pasting process to make the plates moisture conform to the specification without cracks.

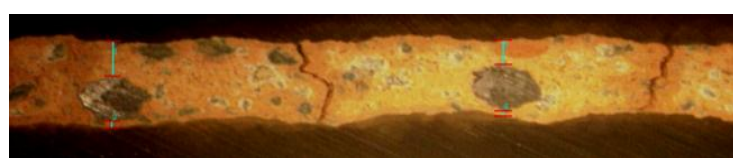

(a)

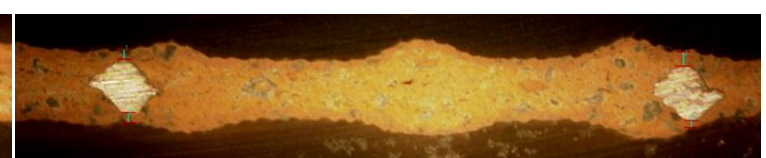

(b)

Fig. 1. Dried plate image through a microscope: (a) crack on plate (b) good condition plate.

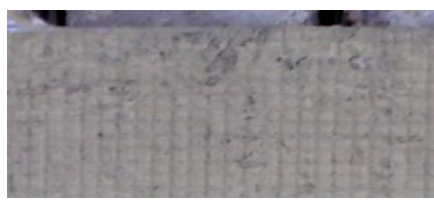

(a)

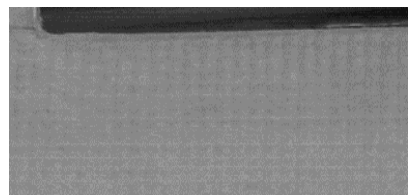

(b)

Fig. 2. Dried plate image: (a) soaked plate (b) good condition plate.

\subsection{Problem analysis and variable screening}

To identify the optimal conditions for acid coating, the input variables or factors that might affect the plate moisture and cracks in the case study factory are investigated. The new pasting process is observed thoroughly. The research team comprising quality control engineers, production engineers, and pasting 
shop operators brainstorms to determine the influential factors to create a cause and effect diagram. By analyzing the cause and effect diagram, five factors that can cause cracks and soaked plates are selected. Four factors, which are the acid roller pressure, the acid flow rate, the baking temperature, and the type of acid roller are selected from the acid coating process. The other is paste moisture, which is a material quality. Some factors such as operator skill, type of sulfuric acid, type of oven, conveyor speed etc. are ignored because of the technical and practical reasons discussed by the research team. The specific gravity of the sulfuric acid is controlled in the range of $1.150 \pm 0.05$ at $20^{\circ} \mathrm{C}$. Although conveyor speed is inversely related to the acid exposure time and the baking time, which affect the volume of acid on the plate surface, it is not selected to do the experiment because of the production yield effect. It is set at 150 plates per minute.

Two factors, which are the type of acid roller and paste moisture, are screened out after preliminary experiments. Three types of acid roller are considered. The first type is made of polyurethane rubber with a smooth surface. Its hardness is 70 shore A. The second type is made from the same material as the first type but with a lattice surface. The size of the lattice is $2 \times 2 \mathrm{~mm}$. with a depth of $1 \mathrm{~mm}$. The last one is made of $5 \mathrm{~mm}$. thick sponge rollers bound around PVC spindles. They are shown in Figs. 4 (a) - (c) respectively. These rollers are installed in the present process to preliminarily test their efficiency.

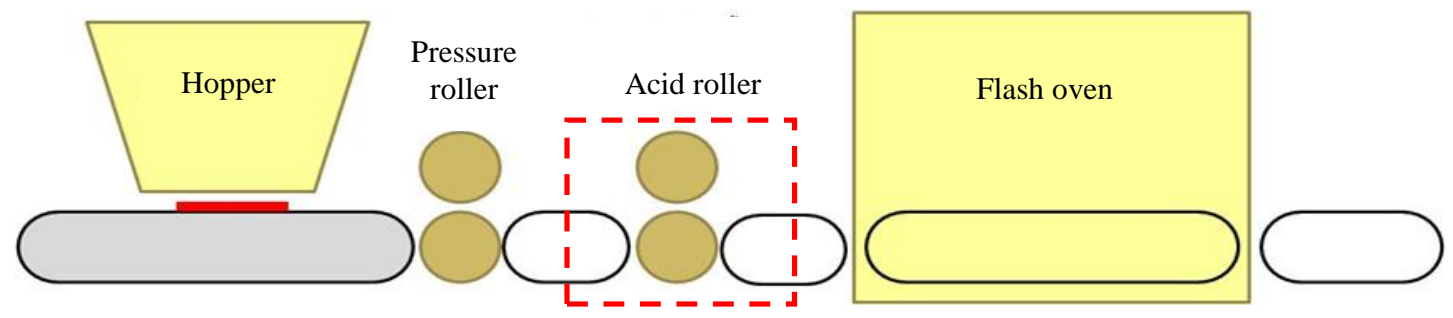

Fig. 3. The experimental pasting process.

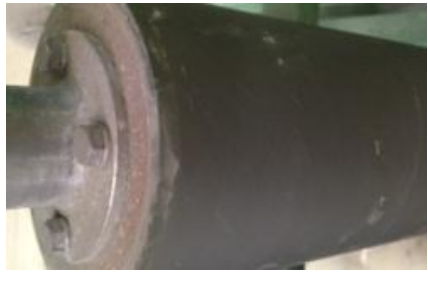

(a)

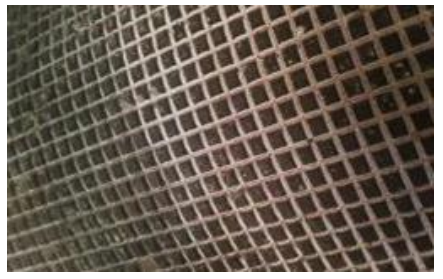

(b)

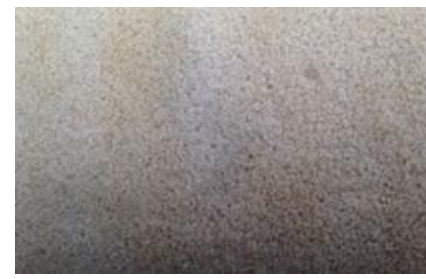

(c)

Fig. 4. Types of acid roller: (a) smooth surface (b) lattice surface (c) sponge surface.

Ten plates coated by each type of roller are collected. The lead sulfate $\left(\mathrm{Pb}_{2} \mathrm{SO}_{4}\right)$ films on these thirty plates are inspected by microscope. The results show that a $\mathrm{Pb}_{2} \mathrm{SO}_{4}$ film is formed on the plates which are thoroughly coated by sponge rollers. For the lattice surface rollers, a partial spread of $\mathrm{Pb}_{2} \mathrm{SO}_{4}$ film is found. $\mathrm{The}_{\mathrm{Pb}} \mathrm{SO}_{4}$ film is not found on the plate coated by smooth surface rollers. Therefore, the sponge roller is selected for the new process. The others are screened out.

Paste moisture coming out of the paste mixing process is controlled in the range of $11 \%-13 \%$. To primarily investigate the effect of paste moisture, the moisture of sixty samples of dried plates in which half come from the paste with moisture at $11 \%-12 \%$ and the other half comes from the paste with moisture at $12 \%-13 \%$, are collected. Before the following hypothesis is tested, two-sample $t$-tests at a significance level $(\alpha)=0.05$ are performed to prove that the data have a normal distribution.

$$
\begin{aligned}
& \mathrm{H}_{0}: \mu_{(11 \%-12 \%)}=\mu_{(12 \%-13 \%)} \\
& \mathrm{H}_{1}: \mu_{(11 \%-12 \%)} \neq \mu_{(12 \%-13 \%)}
\end{aligned}
$$

The results from Minitab show that the $p$-value $=0.633$, which is greater than $\alpha=0.05$. Therefore, the null hypothesis cannot be rejected. The means of plate moisture coming from both paste moisture ranges 
are the same. Thus paste moisture is deleted from the input factors to be experimented. After the screening step, two input factors that are the type of roller, and paste moisture are screened out and their values are fixed.

\subsection{Experimental design and implementation}

Three remaining factors, which are acid roller pressure, acid flow rate, baking temperature, are tested with CCD with two levels of the three factors. Alpha is determined at 1 in RSM using Minitab. A low level of acid roller pressure is set at 0 (no pressure). As suggested in [10], no pressure should be applied on the plate in the coating process because surface tension can cause cracks. A high level of acid roller pressure is set at 0.2 because it is the maximum value that is not over the minimum pressure of the pressure rollers in the previous step $(0.25 \mathrm{MPa})$. If it is set at more than this, the paste will be compressed too flat and the paste thickness will be lower than the specification. A low level of acid flow rate is set at 4 liters/minute because it is the minimum value that makes the acid flow in the entire pipe and can cover the surface of the plates thoroughly. The high level of acid flow rate is limited at 8 to prevent too much acid usage and acid splash. For low and high levels of baking temperature, the ovens are set at $200^{\circ} \mathrm{C}$ and $240^{\circ} \mathrm{C}$ respectively, which are the lowest and highest temperatures used in the original process. The level of the factors at the axial point of these factors using Alpha $=1$ are the center between their low and high levels. The factors and the levels to perform the experiment are presented in Table 1.

Table 1. Input factors and the levels of input factors

\begin{tabular}{lccccc}
\hline Factors & Variables & Unit & Low & Alpha (=1) & High \\
\hline Acid roller pressure & $\mathrm{A}$ & $\mathrm{MPa}$ & 0 & 0.1 & 0.2 \\
Acid flow rate & $\mathrm{B}$ & Liters/minute & 4 & 6 & 8 \\
Baking temperature & $\mathrm{C}$ & ${ }^{\circ} \mathrm{C}$ & 200 & 220 & 240 \\
\hline
\end{tabular}

The power of the design experiment for three factors at three levels, are each performed with two replications at $\alpha=0.05$ using the "Power and Sample Size" function in the "Stat" menu of Minitab. The result shows that the power is equal to 0.99937 or $99.937 \%$, which is greater than $80 \%$. The result means the sample sizes from the experiments can explain $99.937 \%$ of the real process. Therefore, the number of runs is enough to represent the real process. The sequence of combinations of the experiment (treatments) is performed randomly.

Three factors in the trial process are set according to the sequence of treatments. Forty treatments are performed. For each treatment, two responses are recorded. The first response $\left(y_{1}\right)$ is dried plate moisture that is measured by hydrometer. The other $\left(y_{2}\right)$ is the number of cracks on the dried plate surface.

\subsection{Experimental analysis}

The results are tested with analysis of variance (ANOVA) and created the response surface. The response surface equation is then used to set the optimum level of input factors that maximizes the value of $y_{1}$ and minimizes the value of $y_{2}$ simultaneously using the "Response Optimizer" in Minitab. The setting values in the "Response Optimizer" function for $y_{1}$ and $y_{2}$ shown in Fig. 5 are set according to quality specifications. Weight is set at 1 because linear desirability is of interest. Importance for $y_{1}$ and $y_{2}$ is set at 0.1 and 1.7 because of the failure cost ratio. If there is a crack, it costs 17 times more than soaked plates.

\begin{tabular}{|c|c|c|c|c|c|c|c|}
\hline Response & & & Lower & Target & Upper & Weight & Importance \\
\hline y1 & Maximize & - & 0.085 & 0.095 & 0.095 & 1 & 0.1 \\
\hline$y 2$ & Minimize & $=$ & 0 & 0 & 0.9 & 1 & 1.7 \\
\hline
\end{tabular}

Fig. 5. Value set up in the response optimizer for $y_{1}$ and $y_{2}$. 


\subsection{Experimental verification}

Before using the optimal combination derived from the previous section as a working standard, another set of experiments is performed to verify the replicability of the experiment.

\section{Results and Discussion}

This part comprises two sections. The first section presents the experimental results and the interpretation of results. The other section presents the results of experiment verification.

\subsection{The experimental results and analysis}

The percentage of plate moisture (\%) and the number of cracks (points) in a 40-run experiment are summarized in Table 2. The ANOVA table for these results is shown in Fig 6.

Table 2. The experimental results (unit of $y_{1}$ is a percentage and unit of $y_{2}$ is a point)

\begin{tabular}{|c|c|c|c|c|c|c|c|c|c|c|}
\hline \multirow{3}{*}{$\begin{array}{l}\text { A: Acid } \\
\text { roller } \\
\text { pressure } \\
(\mathrm{MPa})\end{array}$} & \multirow{3}{*}{$\begin{array}{c}\text { Value } \\
\text { of }\end{array}$} & \multicolumn{9}{|c|}{ B: Acid flow rate (liters/minute) } \\
\hline & & \multicolumn{3}{|c|}{$\begin{array}{c}4 \\
\mathrm{C}: \text { Baking temperature }\left({ }^{\circ} \mathrm{C}\right)\end{array}$} & \multicolumn{3}{|c|}{$\begin{array}{c}6 \\
\text { C: Baking temperature }\left({ }^{\circ} \mathrm{C}\right)\end{array}$} & \multicolumn{3}{|c|}{$\begin{array}{c}8 \\
\mathrm{C}: \text { Baking temperature }\left({ }^{\circ} \mathrm{C}\right)\end{array}$} \\
\hline & & 200 & 220 & 240 & 200 & 220 & 240 & 200 & 220 & 240 \\
\hline \multirow[t]{2}{*}{0} & $y_{1}$ & 1,1 & & 6,6 & & 0,0 & & 0,0 & & 2,3 \\
\hline & $y_{2}$ & $9.36,9.37$ & - & $9.10,9.08$ & - & $9.22,9.23$ & & $9.59,9.59$ & - & $9.17,9.18$ \\
\hline \multirow[t]{2}{*}{0.1} & $y_{1}$ & & 1,2 & & 0,0 & $0,0,1,1,0,1,0,1,0,0,1,0$ & 2,3 & & 0,0 & \\
\hline & $y_{2}$ & - & $9.24,9.25$ & - & $9.45,9.46$ & $\begin{array}{c}9.38,9.28,9.31,9.34 \\
9.29,9.30,9.39,9.30 \\
9.32,9.36,9.35,9.33\end{array}$ & $9.14,9.15$ & - & $9.21,9.23$ & - \\
\hline \multirow[t]{2}{*}{0.2} & $y_{1}$ & 1,2 & & 5,7 & & 0,0 & - & 0,0 & - & 3,3 \\
\hline & $y_{2}$ & $9.38,9.39$ & & $9.02,9.03$ & & $9.20,9.25$ & & $9.62,9.62$ & & $9.19,9.18$ \\
\hline
\end{tabular}

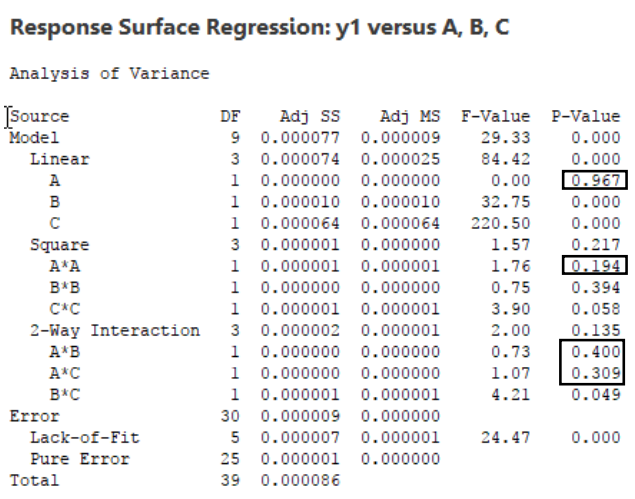

(a)

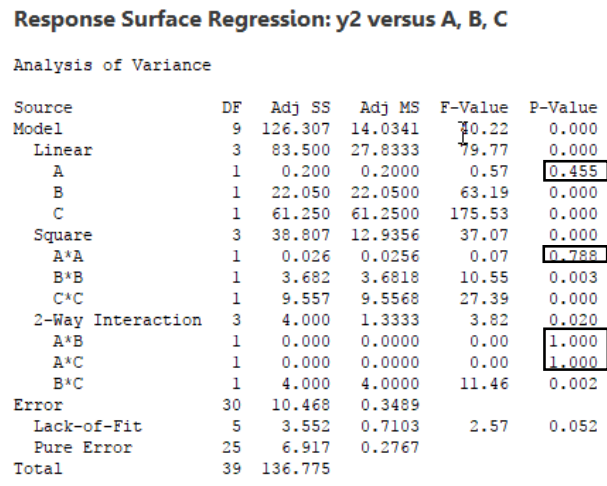

(b)

Fig. 6. ANOVA table for: (a) $y_{1}$ and (b) $y_{2}$.

According to the ANOVA table, factor A does not affect either response significantly because the $p$ values for both main factors and the interaction between $\mathrm{A}$ and the other factors are greater than $\alpha=0.05$. These terms are marked with square boxes in Fig. 6 (a) and (b). This factor is set at 0 (no pressure applied on plates) because of product crack prevention, the reduction of roller erosion, and production economy. The optimal value for factors $\mathrm{B}$ and $\mathrm{C}$ are set by considering the combination of regression equations in the un-coded units of $y_{1}$ and $y_{2}$ expressed in Eq.(1) and Eq.(2) respectively. The optimal values for factors $\mathrm{B}$ and $\mathrm{C}$ from the response optimizer shown in Fig.7 (a) are at 6.6667 litres/minute and $201.1078^{\circ} \mathrm{C}$ respectively. The desirability (D) is 1 . The values are rounded off to 7 litres/minute and 
$200^{\circ} \mathrm{C}$ in order to conform to the machine setup capability. The predicted values of $y_{1}$ and $y_{2}$ at $\mathrm{A}=0$ $\mathrm{MPa}, \mathrm{B}=7$ litres/minute and $\mathrm{C}=200^{\circ} \mathrm{C}$ shown in Fig. 7 (b) are 0.0952 or $9.52 \%$ and -0.3114 points (no cracks found on the plate) respectively, which conform to the plate specification.

$$
\begin{aligned}
& y_{1}=0.1397+0.002808 B-0.000421 C-0.000078 B^{2}+0.000001 C^{2}-0.000007 B C \\
& y_{2}=137.8-0.31 B-1.316 C+0.2109 B^{2}+0.003359 C^{2}-0.01250 B C
\end{aligned}
$$

\subsection{Results of experimental verification}

To verify the repeatability of the results, another set of experiments where factors $\mathrm{A}, \mathrm{B}$ and $\mathrm{C}$ are at 0 $\mathrm{MPa}, 7$ liters/minutes and $200^{\circ} \mathrm{C}$ is conducted. Thirty runs of the experiments are completed. The $95 \%$ confidence interval of $y_{1}$ is $(9.5163,9.5230)$ which is in the specification interval $(9.5 \pm 1 \%)$ and $y_{2}=0$. This result guarantees that the selected setting increases plate moisture and causes no cracks.

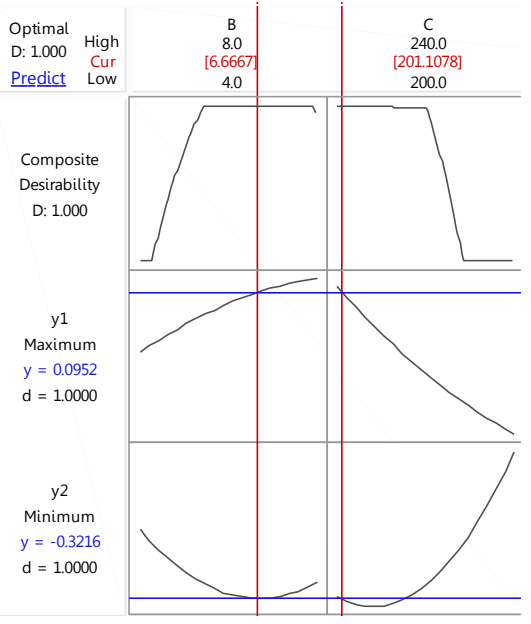

(a)

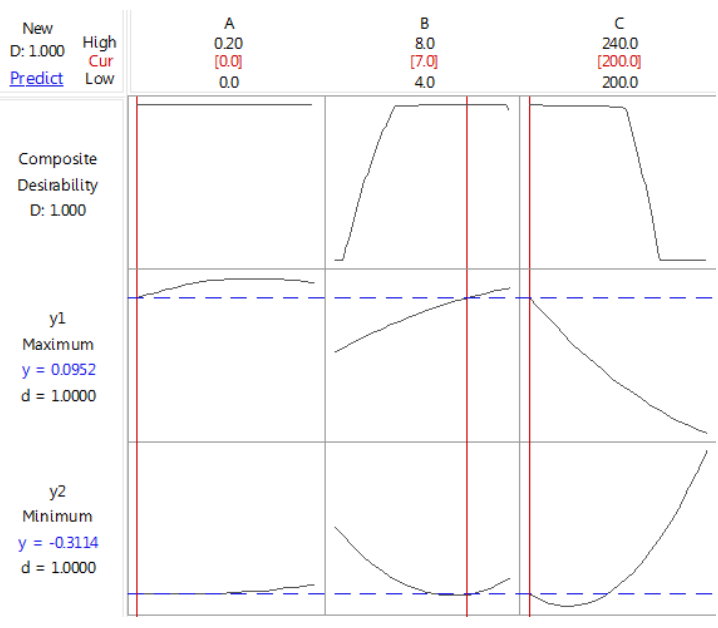

(b)

Fig. 7. (a) Optimal value of factor B and C (b) Predicted value of $y_{1}$ and $y_{2}$ at the selected setting.

\section{Conclusions}

The quality of the battery plate can be enhanced by sulfuric acid coating. The average moisture increases by $4.74 \%$. The $95 \%$ confidence interval for plate moisture moves from the lower side of the specification limit $(9.010,9.168)$ to the middle of the specification $(9.516,9.523)$. This condition reduces the chance of cracks. Three factors that affect plate moisture and the number of cracks in the acid coating system are considered. Acid flow rate and baking temperature significantly affect both responses while acid roller pressure does not. The optimal settings for the first two factors are 7 liters/minute and $200^{\circ} \mathrm{C}$ respectively. The acid roller pressure is set at $0 \mathrm{MPa}$ or no pressure applied because this condition extends roller life, reduces maintenance requirements and is convenient for process setup.

For future research, this work can be extended to working standards and manuals for general sulfuric acid coating processes. The various parameters, such as the specific gravity of sulfuric acid, the type of battery plate, the conveyor speed, paste moisture etc. should be investigated for general acid coating applications.

\section{References}

[1] Chang Y, Mao X, Zhao Y, Feng S, Chen H, Finlow D. Lead-acid use in the development of renewable energy systems in China. Journal of Power Sources, 2009; 191(1): 176-183. 
[2] Han L, Rafique SF, Jianhua Z. Implementation of battery management module for the microgrid: a case study. International Journal of Smart Grid and Clean Energy, 2017; 6(1): 11-20.

[3] Dahodwalla H, Herat S. Cleaner production options for lead-acid battery manufacturing industry. Journal of Cleaner Production, 2000; 8 (2000): 133-142.

[4] Lashway CR, Idowu P. A test system for advanced lead acid battery state-of-charge and state-of-health research. International Journal of Smart Grid and Clean Energy, 2016; 5(1): 41-55.

[5] Kwiecien M, Schröer P, Kuipers M, Sauer DU. Current research topics for lead-acid batteries. In: Jürgen G, Karden E, Moseley PT, Rand DAJ, editors. Lead-Acid Batteries for Future Automobiles, Amsterdam: Elsevier; 2017: 133 - 146.

[6] Rus EM, Constantin DM, Taralunga G, Rus Al. The infulence of curing process on the lead-acid battery performance. Presented at: 2005 Advanced Batteries and Accumulators.

[7] Palov D. Lead-Acid Batteries: Science and Technology. 1st ed., Amsterdam: Elsevier Science; 2011.

[8] Nattaporn V. Master of Engineering Program in Engineering Management. MS dissertation Department of Industrial Engineering. Kasetsart University. Bangkok, Thailand; 2017.

[9] Montgomery DC. Design and Analysis of Experiments. 8th ed., New York: John Wiley \& Sons, Inc.; 2012.

[10] Musil J, Sklenka J, Prochazka. Protective over-layer coating preventing cracking of thin films deposited on flexible substrates. Surface \& Coatings Technology, 2014; 240 (2014): 275-280. 